Page 1 of $2 \quad \quad \begin{aligned} & \text { Proj. } \\ & \text { ECN }\end{aligned}$

\begin{tabular}{|c|c|c|c|c|}
\hline \multirow{3}{*}{$\begin{array}{l}\text { 2. ECN Category (mark one) } \\
\text { Supplemental } \\
\text { Direct Revision } \\
\text { Change ECN } \\
\text { Temporary } \\
\text { Standby } \\
\text { Supersedure } \\
\text { CancelNoid }\end{array}$} & \multicolumn{2}{|c|}{$\begin{array}{l}\text { 3. Originator's Name, Organization, MSIN, and Telephone No. } \\
\text { A. L. Ramble, BWHC, T5-54, 373-2185 }\end{array}$} & $\begin{array}{l}\text { 4. USQ Required? } \\
\text { Yes O No }\end{array}$ & $\begin{array}{l}\text { 5. Date } \\
9 / 10 / 99\end{array}$ \\
\hline & $\begin{array}{l}\text { 6. Project Title/No. Work Order No. } \\
\text { CSER 9A-013: Classification and Access to PFP 232-z } \\
\text { Incinerator Facility and Limits on Characterization and } \\
\text { Disassembly Activities in 232-z Burning Hood }\end{array}$ & \multicolumn{2}{|c|}{ 7. Bldg./Sys./Fac. No. } & 8. Approval Designator \\
\hline & $\begin{array}{l}\text { 9. Document Numbers Changed by this ECN (includes } \\
\text { sheet no. and rev.) }\end{array}$ & \multicolumn{2}{|c|}{ 10. Related ECN No(s). } & $\begin{array}{l}\text { 11. Related PO No. } \\
\text { N/A }\end{array}$ \\
\hline $\begin{array}{l}\text { 12a. Modification Work } \\
\text { Yes (fill out Blk. 12b) } \\
\text { No (NA Blks. 12b, } \\
\qquad \begin{array}{l}\text { (2c, 12d) } \\
\end{array}\end{array}$ & $\begin{array}{l}\text { 12b. Work Package No. } \\
\text { N/A }\end{array}$ & $\begin{array}{l}\text { 12c. Modification Work Completed } \\
\text { N/A } \\
\text { Design Authority/Cog. Engineer Signature \& } \\
\text { Date }\end{array}$ & \multicolumn{2}{|c|}{$\begin{array}{l}\begin{array}{l}\text { 12d. Restored to Original Condition (Temp. } \\
\text { or Standby ECNs only) }\end{array} \\
\text { N/A } \\
\text { Design Authority/Cog. Engineer Signature \& } \\
\text { Date }\end{array}$} \\
\hline
\end{tabular}

14a. Justification (mark one) $14 \mathrm{~b}$. Justification Details

Criteria Change O This CSER supported clean out of the 232-z Burning Hood and is no longer

Design Improvement $O$ needed. Cancellation of this CSER is directed by BWHC letter

Environmental $\bigcirc$ BWHC-15500-98-018.

Facility Deactivation

As-Found

0

Facilitate Const.

0

Const. Error/Omission

Design Error/Omission

15. Distribution (include name, MSIN, and no. of copies)

See attached Distribution List 


\section{ENGINEERING CHANGE NOTICE}

16. Design Verification Required
Yes
O No

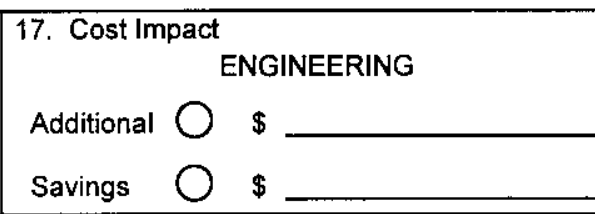

\begin{tabular}{ll} 
& \multicolumn{2}{c}{ CONS } \\
Additional & $\bigcirc$ \\
Savings & $\$$
\end{tabular}

1. ECN (use no. from pg. 1)

654897

18. Schedule Impact (days)

Improvement $\bigcirc$

Delay

19. Change Impact Review: Indicate the related documents (other than the engineering documents identified on Side 1) that will be affected by the change described in Block 13. Enter the affected document number in Block 20.

SDD/DD

Functional Design Criteria

Operating Specification

Criticality Specification

Conceptual Design Report

Equipment Spec.

Const. Spec.

Procurement Spec.

Vendor Information

OM Manual

FSAR/SAR

Safety Equipment List

Radiation Work Permit

Environmental Impact Statement

Environmental Report

Environmental Permit $\square$

$\square$

$\square$

$\square$

$\square$

$\square$

$\square$

$\square$

$\square$

$\square$

$\square$

$\square$
Fac. Proc. Samp. Schedule

Inspection Plan

Inventory Adjustment Request

Seismic/Stress Analysis
Stress/Design Report
Interface Control Drawing
Calibration Procedure
Installation Procedure
Maintenance Procedure
Engineering Procedure
Operating Instruction
Operating Procedure
Operational Safety Requirement
IEFD Drawing
Cell Arrangement Drawing
Essential Material Specification
Fac. Proc. Samp. Schedule
Inspection Plan
Inventory Adjustment Request

Tank Calibration Manual Health Physics Procedure Spares Multiple Unit Listing Test Procedures/Specification Component Index ASME Coded Item Human Factor Consideration Computer Software Electric Circuit Schedule ICRS Procedure Process Control Manual/Plan Process Flow Chart

Purchase Requisition

Tickler File

Cricate that tha sinning

20. Other Affected Documents: (NOTE: Documents listed below will not be revised by this ECN.) Signatures below indicate that the signing organization has been notified of other affected documents listed below.

\section{Signature}

Date

Design Authority M. E. Shaw T5-50\% Cog. Eng. A. L. Ramble $55-54 / \mathrm{L}$ Cog. Mgr. P. E. Roege T5-57/4ta QA Safety D.A. Cenniers Environ.

Other CSE R. F. Richard B. Fithatand
T/14/59 ilistis $9 / 15 / 54$
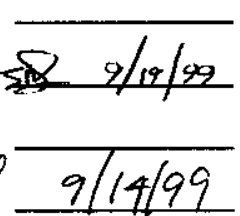

Signature

Date

Design Agent

PE

QA

Safety

Design

Environ.

Other

\section{DEPARTMENT OF ENERGY}

Signature or a Control Number that tracks the Approval Signature

\section{ADDITIONAL}




\title{
CSER 94-013: CLASSIFICATION AND ACCESS TO PFP 232-Z INCINERATOR FACILITY AND LIMITS ON CHARACTERIZATION AND DISASSEMBLY ACTIVITIES IN 232-Z BURNING HOOD
}

\author{
A. L. Ramble \\ B $\& W$ Hanford Company \\ Richland, WA 99352 \\ U.S. Department of Energy Contract DE-AC06-96RL13200

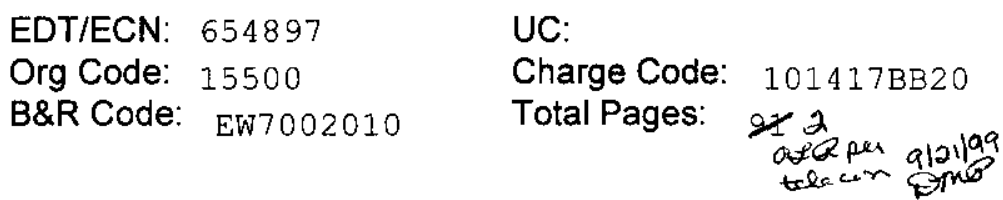 \\ Key Words: $232-\mathrm{z}$ Incinerator, PFP, Burning Hood
}

Abstract: This CSER is no longer needed so it is being cancelled

TRADEMARK DISCLAIMER. Reference herein to any specific commercial product, process, or service by trade name, trademark, manufacturer, or otherwise, does not necessarily constitute or imply its endorsement, recommendation, or favoring by the United States Government or any agency thereof or its contractors or subcontractors.

Printed in the United States of America. To obtain copies of this document, contact: Document Control Services, P.O. Box 950, Mailstop H6-08, Richland WA 99352, Phone (509) 372-2420; Fax (509) 376-4989.
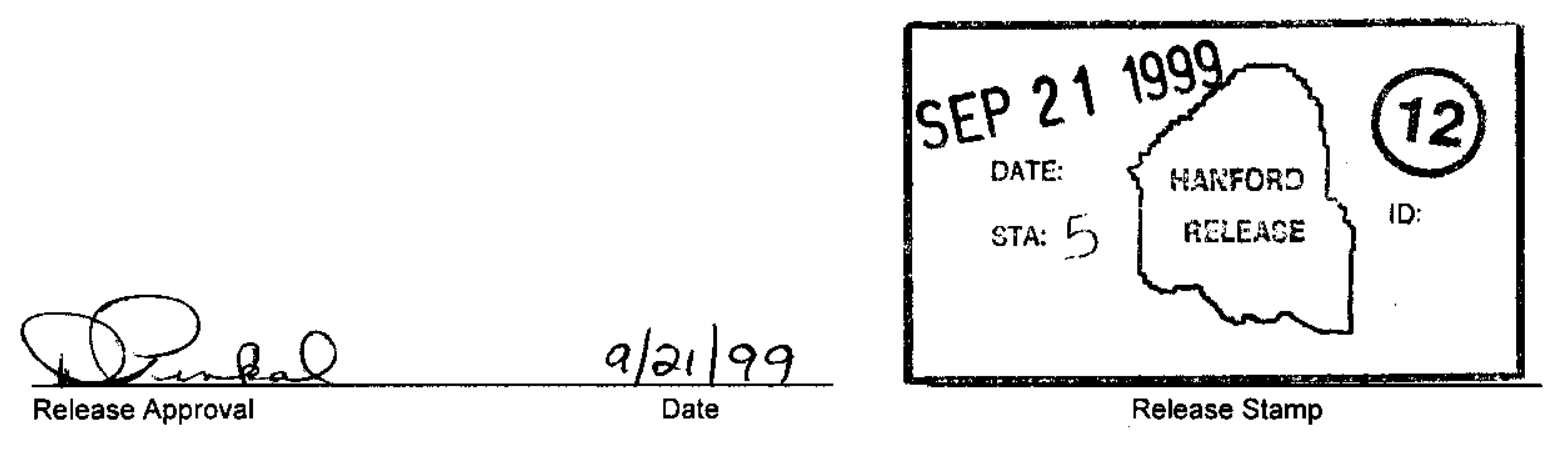

\section{Approved For Public Release}




\section{RECORD OF REVISION}

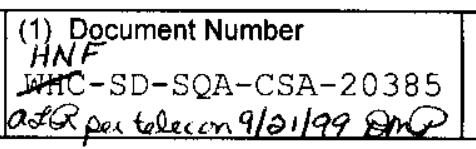

Page 1

(2) Title

CSER 94-013: Classification and Access to PFP 232-Z Incinerator Facility and Limits on Characterization and Disassembly Activities in 232-z Burning Hood

Change Control Record

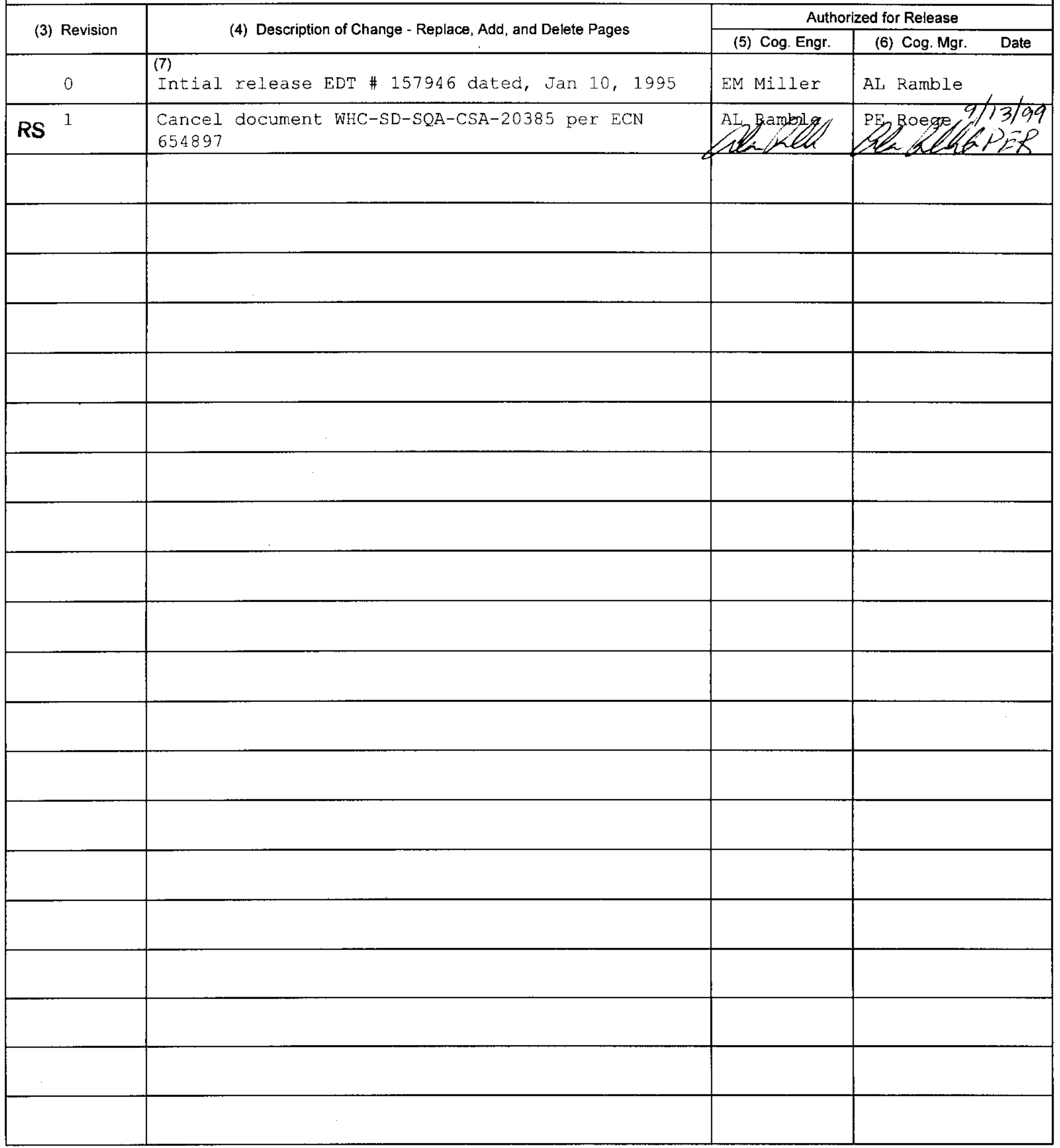




\section{DISTRIBUTION SHEET}

To

Distribution

Project Title/Work Order

CSER 94-013: Classification and Access to PFP 232-Z Incinerator Facility and limits on Characterization and Dissembly Activities in 232-z Burning Hood

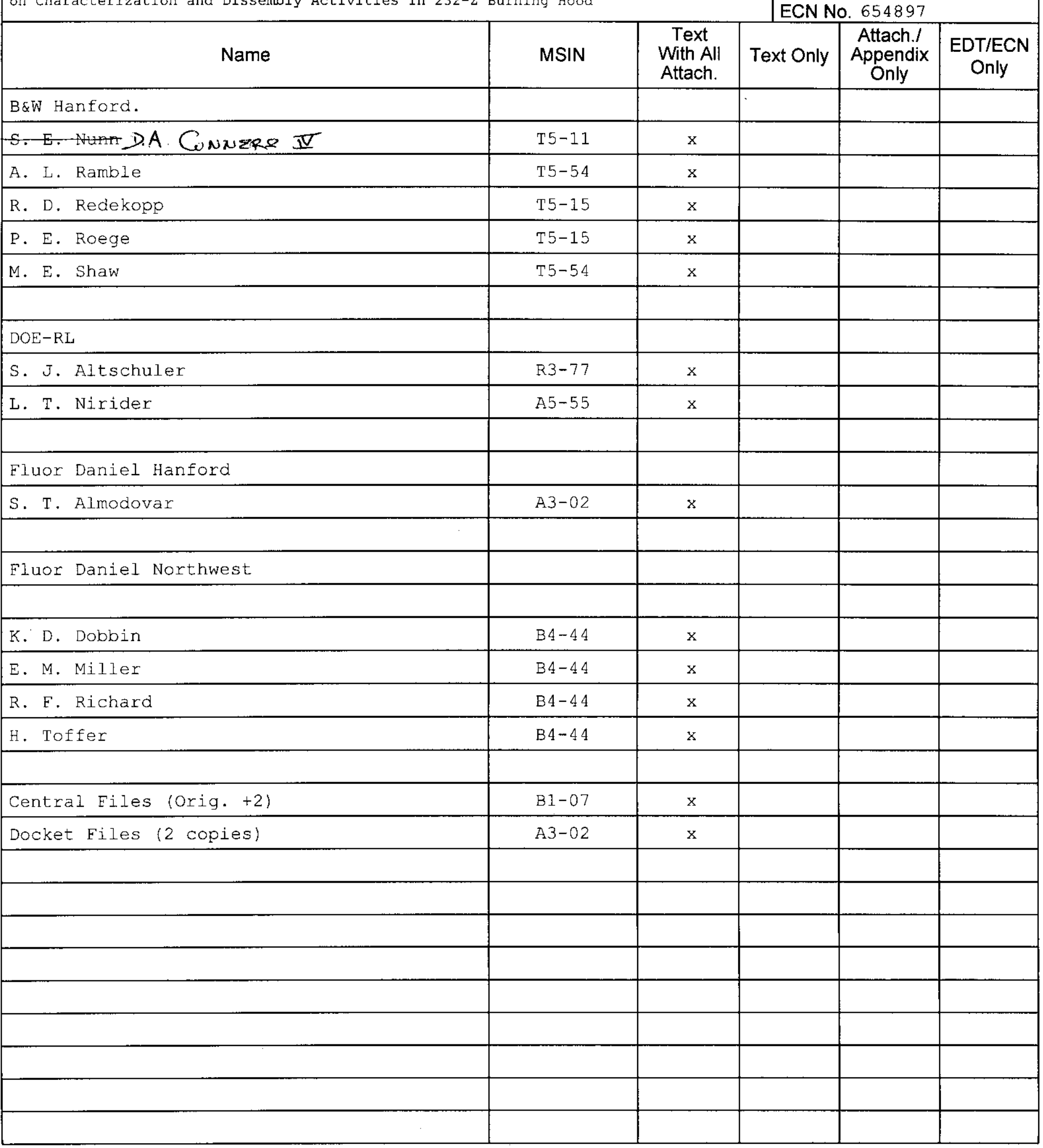

\section{From}

BWHC \begin{tabular}{|lll} 
Page $1 \quad$ of 1 \\
\hline Date & $9 / 10 / 99$ \\
\hline
\end{tabular}

EDT No.

ECN No. 654897

\begin{tabular}{c|c|c|} 
Attach./ & EDT/ECN \\
Oppendix & Only
\end{tabular} 